\title{
Open pore biodegradable matrices formed with gas foaming
}

\author{
Leatrese D. Harris, ${ }^{1}$ Byung-Soo Kim, ${ }^{1}$ David J. Mooney ${ }^{1,2}$ \\ ${ }^{1}$ Department of Chemical Engineering, University of Michigan, Ann Arbor, Michigan 48109-2136 \\ ${ }^{2}$ Department of Biologic and Materials Sciences, University of Michigan, Ann Arbor, Michigan 48109-2136
}

Received 25 July 1997; accepted 22 April 1998

\begin{abstract}
Engineering tissues utilizing biodegradable polymer matrices is a promising approach to the treatment of a number of diseases. However, processing techniques utilized to fabricate these matrices typically involve organic solvents and/or high temperatures. Here we describe a process for fabricating matrices without the use of organic solvents and/or elevated temperatures. Disks comprised of polymer [e.g., poly (D,L-lactic-co-glycolic acid)] and $\mathrm{NaCl}$ particles were compression molded at room temperature and subsequently allowed to equilibrate with high pressure $\mathrm{CO}_{2}$ gas (800 psi). Creation of a thermodynamic instability led to the nucleation and growth of gas pores in the polymer particles, resulting in the expansion of the polymer particles. The polymer particles fused to form a continuous matrix with entrapped salt particles. The $\mathrm{NaCl}$ particles subsequently were leached to yield macropores within the poly-
\end{abstract}

mer matrix. The overall porosity and level of pore connectivity were regulated by the ratio of polymer/salt particles and the size of salt particles. Both the compressive modulus $(159 \pm 130 \mathrm{kPa}$ versus $289 \pm 25 \mathrm{kPa})$ and the tensile modulus $(334 \pm 52 \mathrm{kPa}$ versus $1100 \pm 236 \mathrm{kPa})$ of the matrices formed with this approach were significantly greater than those formed with a standard solvent casting/particulate leaching process. The utility of these matrices was demonstrated by engineering smooth muscle tissue in vitro with them. This novel process, a combination of high pressure gas foaming and particulate leaching techniques, allows one to fabricate matrices with a well controlled porosity and pore structure. This process avoids the potential negatives associated with the use of high temperatures and/or organic solvents in biomaterials processing. (C) 1998 John Wiley \& Sons, Inc. J Biomed Mater Res, 42, 396-402, 1998.

\section{INTRODUCTION}

The lack of autologous and allogeneic tissue suitable for transplantation has driven the development of the tissue engineering field in which new tissues are created from cultured cells and biomaterials. ${ }^{1}$ The advantages of this approach include the ability to expand cells in vitro. Thus an initially small number of cells can be used to treat multiple patients, or cells from a small biopsy can be expanded to fill a large defect. The biomaterial serves as a vehicle to localize the cells of interest, as a physical spacer to create potential space for tissue development, and as a template guiding tissue regeneration. Biodegradable homopolymers and copolymers of lactide and glycolide are attractive can-

Correspondence to: D. J. Mooney; e-mail: mooneyd@engin. umich.edu

Contract grant sponsor: GEM Consortium (to L. D. H.)

Contract grant sponsor: National Science Foundation; Contract grant number: BES-9501376

Contract grant sponsor: Reprogenesis

(C) 1998 John Wiley \& Sons, Inc. $\quad$ CCC 0021-9304/98/030396-07 didates for fabricating tissue engineering matrices due to their flexible and well defined physical properties and relative biocompatibility. ${ }^{2}$ Additionally, the degradation products of these polymers are natural metabolites and as such readily are removed from the body.

Several techniques have been used to fabricate polymers into porous matrices for tissue engineering applications, including solvent-casting/particulate leaching (SC/PL), ${ }^{3}$ phase separation, ${ }^{4}$ fiber extrusion and fabric forming processing, ${ }^{5}$ and gas foaming. ${ }^{6}$ The solvent-casting/particulate leaching and phase separation approaches require the use of organic solvents. Residues of organic solvents, which can remain in these polymers after processing, may damage transplanted cells and nearby tissue and inactivate many biologically active factors (e.g., growth factors) that one might wish to incorporate into the polymer matrix for controlled release. Fiber forming typically requires high temperatures (above the transition temperature of polymer) and is not amenable to processing amorphous polymers. The high temperatures used in this 
process also are likely to denature any biologically active molecules one might wish to incorporate into the matrix.

Recently, we described a technique for fabricating highly porous matrices from poly (lactic-co-glycolic acid) (PLGA) using a high pressure gas technique that avoids the use of organic solvents and high temperatures. ${ }^{6}$ However, these types of gas foaming methods $^{6,7}$ typically yield a closed pore structure, which is disadvantageous in many applications of cell transplantation. In addition, a solid skin of polymer results on the exterior surface of the foamed matrix ${ }^{7}$ and this is often undesirable. We now have modified this process to enable the fabrication of highly porous matrices with levels of pore connectivity anywhere between predominantly interconnected and closed. The porosity and pore structure are regulated by processing parameters. These porous matrices can be seeded with cells and provide a suitable structure for the regeneration of tissues. The seeded cells adhere to the matrix, proliferate, and form new three-dimensional tissues in vitro.

\section{MATERIALS AND METHODS}

\section{Matrix processing}

Pellets of an 85:15 copolymer of D,L-lactide and glycolide (PLGA) were purchased from Boehringer Ingelheim (Henley, Montvale, New Jersey) and utilized to fabricate polymer matrices for all experiments. The intrinsic viscosity of the polymer was $~ 1.3-1.7$. Polymer pellets were ground using a Tekmar grinder (Bel-Art Products, Pequannock, New Jersey) and sieved to obtain particles ranging from 106 to $250 \mu \mathrm{m}$. In certain experiments, the polymer particles were mixed with sodium chloride particles (Mallinkrodt, Paris, Kentucky). The salt particles were sieved to yield a range of sizes, and the ratio of $\mathrm{NaCl} / \mathrm{PLGA}$ masses ranged from 0 to 50 . In all cases, the total mass of PLGA and $\mathrm{NaCl}$ was held constant at $0.8 \mathrm{~g}$. The mixtures of PLGA and $\mathrm{NaCl}$ were loaded into a $\mathrm{KBr}$ die $(1.35 \mathrm{~cm}$ in diameter; Aldrich Chemical Co., Milwaukee, Wisconsin) and compressed at 1500 psi for $1 \mathrm{~min}$ using a Carver Laboratory Press (Fred S. Carver, Inc., Menominee Falls, Wisconsin) to yield solid disks (thickness $=3.4$ $\mathrm{mm})$. The samples then were exposed to high pressure $\mathrm{CO}_{2}$ gas ( $800 \mathrm{psi})$ for $48 \mathrm{~h}$ to saturate the polymer with gas. A thermodynamic instability then was created by decreasing the gas pressure to ambient pressure. This led to the nucleation and growth of $\mathrm{CO}_{2}$ pores within the polymer matrices. The $\mathrm{NaCl}$ particles subsequently were removed from the matrices by leaching the matrices in $\mathrm{ddH}_{2} \mathrm{O}$ for $48 \mathrm{~h}$. All processing steps were performed at ambient temperature.

Porous sponges also were fabricated using a previously described solvent casting-particulate leaching technique. ${ }^{3}$ In this process, PLGA was dissolved in chloroform (Mallinkrodt; Paris, Kentucky) to yield a solution of $10 \%(\mathrm{w} / \mathrm{v})$, and $0.12 \mathrm{~mL}$ of this solution was loaded into Teflon cylinders (diameter $=21.5 \mathrm{~cm}$, height $=25 \mathrm{~mm}$; Cole Parmer) packed with $0.4 \mathrm{~g}$ of sodium chloride particles sieved to a size between 250 and $500 \mu \mathrm{m}$. Following solvent evaporation, polymer films with entrapped salt particles (3 mm thick) carefully were removed from the molds. The salt was removed by immersing films in distilled water for $48 \mathrm{~h}$.

\section{Characterization}

The porosity of samples initially was determined by gross measurements and weights after processing using the following equation:

$$
\text { porosity }(\%)=1-[(\text { weight } / \text { volume }) / \rho \text { polymer }] \times 100(1)
$$

The porosity also was measured using mercury intrusion porosimetry (Autscan-500, Quantachrome, Syosset, NY) for certain samples. A contact angle for mercury on PLGA of $132^{\circ}$ was used for this analysis.

The samples were imaged using a scanning electron microscope (ISI-DS 130, Topcon Technologies, Pleasanton, CA,). The samples were gold coated using a sputter coater (Desk II, Denton Vacuum, Cherry Hill, New Jersey), and the microscope was operated at $10 \mathrm{kV}$ to image the samples. Polaroid 55 film was used for the photomicrographs. The pore diameter of GF/PL matrices fabricated with various $\mathrm{NaCl}$ particle size was measured from SEM photomicrographs of four different areas of each matrix.

Compression and tensile testing were performed on an MTS Bionix 100 (Sintech, Research Triangle Park, North Carolina). Samples were cut into $1 \times 1 \mathrm{~cm}$ squares for compression testing. For tensile testing, the samples $(1 \times 1 \mathrm{~cm})$ were attached to cardboard using epoxy glue. A $7 \mathrm{~mm}$ slot was cut into the center of the card board and the sample was centered, then glued to standardize the gauge length. Compression and tensile tests were performed with a constant strain rate $(1 \mathrm{~mm} / \mathrm{min})$. The moduli were determined from the slopes in the elastic portion of the stress-strain diagram.

Thermogravimetric analysis (ATI/Cahn TG-121, Madison, Wisconsin) was utilized to determine the amount of salt residue that remained in the sponge after leaching. Matrices were heated from $150^{\circ} \mathrm{C}$ to $300^{\circ} \mathrm{C}$ at a constant rate of $10^{\circ} \mathrm{C} /$ $\mathrm{min}$, and the residual mass was monitored.

\section{Cell studies}

Smooth muscle cells (SMC) were used in all experiments. SMCs were isolated and cultured using a modification of the techniques described in Rothman et al. ${ }^{8}$ In brief, the cells were isolated from aortas of 300-350 g adult male Lewis rats (Charles River Laboratories, Wilmington, Massachusetts) using an enzymatic dissociation. After fat, adventitia, and connective tissue surrounding the arteries were removed by blunt dissection, the SM tissue was cut into multiple small pieces and placed into a spinner flask containing an enzymatic dissociation buffer at $37^{\circ} \mathrm{C}$. This buffer contained 0.125 $\mathrm{mg} / \mathrm{mL}$ elastase (Sigma Chemical Co., St. Louis, Missouri), $1.0 \mathrm{mg} / \mathrm{mL}$ collagenase (CLS type I, 204 units/mg, Wor- 
thington Biochemical Corp., Freehold, New Jersey), 0.250 $\mathrm{mg} / \mathrm{mL}$ soybean trypsin inhibitor (type 1-S, Sigma), and 2.0 $\mathrm{mg} / \mathrm{mL}$ crystallized bovine serum albumin (BSA, Gibco/ Life Technologies, Gaithersburg, Maryland). After 90 min of incubation, the suspension was filtered through a $100 \mu \mathrm{m}$ Nitex filter (Tetko, Inc., Briarcliff Manor, NY) and centrifuged at $200 \mathrm{~g}$ for $5 \mathrm{~min}$. The pellet was resuspended in Medium 199 (Sigma) supplemented with 20\% (v/v) fetal bovine serum (FBS, Gibco), $2 \mathrm{mM}$ L-glutamine (Gibco), and 50 units/mL penicillin-streptomycin (Gibco). The cells were cultured on tissue culture plastic in a humidified 5\% $\mathrm{CO}_{2}$ atmosphere with the medium [Medium 199, 10\% (v/v) fetal bovine serum, 50 units/mL penicillin-streptomycin] changed every other day. Cells at passage 17 were used in these experiments.

The matrices were seeded with SMCs. Uniform cell seeding was achieved by placing a volume $(40 \mu \mathrm{L})$ of cell suspension $\left(3.14 \times 10^{7}\right.$ cells $\left./ \mathrm{mL}\right)$ sufficient to fill the entire void volume onto each matrix and allowing the cell suspension to adsorb into all spaces of the matrices. The matrices were maintained in tissue culture dishes and incubated at $37^{\circ} \mathrm{C}$ for 36 h. Following the cell seeding, SEM examination confirmed a uniform cell distribution throughout the matrices (not shown). Next, the polymer matrices were cultured for 2 weeks in a spinner flask $(100 \mathrm{~mL}$, Bellco Glass, Inc., Vineland, New Jersey) stirred at 40 RPM. The number of cells in the matrices was determined by measuring the DNA content in enzyme-digested triplicate samples using Hoechst 33258 dye and a fluorometer (Hoefer DyNA Quant 200, Pharmacia Biotech, Uppsala, Sweden) as previously described. ${ }^{9}$ For scanning electron microscopic examination, samples were fixed in $1 \%$ glutaraldehyde and $0.1 \%$ formaldehyde for 30 min and $24 \mathrm{~h}$, respectively, dehydrated in a graded series of ethanol/water solutions, dried, and then sputter coated with gold. A scanning electron microscope (ISI-DS 130, Topcon Technologies) was operated at $10 \mathrm{kV}$ to image samples. Histological sections were prepared by fixing cell-polymer matrices (10\% formalin), dehydrating, embedding, sectioning, and staining with hematoxylin and eosin using standard techniques.

\section{RESULTS}

\section{Integrity and porosity/pore structure of foamed matrices}

Gas foaming solid polymer disks led to the formation of highly porous matrices [Fig. 1(a)]. However, these matrices had a nonporous skin on the external surfaces and the pores were largely closed, as expected from previous studies. ${ }^{6}$ In contrast, foaming and subsequent leaching of disks containing a high percentage $(95 \%)$ of large $(250<\mathrm{d}<425 \mu \mathrm{m}) \mathrm{NaCl}$ particles led to the formation of highly porous, open pore matrices with no evidence of an external, nonporous skin [Fig. 1(b)]. The pore structure observed in cross-sections of these matrices was similar to that observed in cross-sections of matrices formed with a SC/

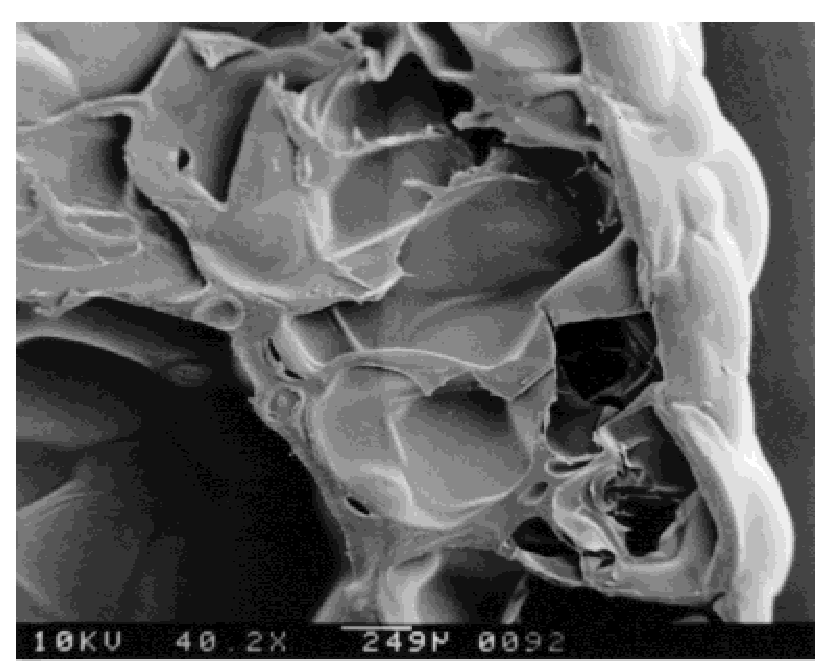

(a)

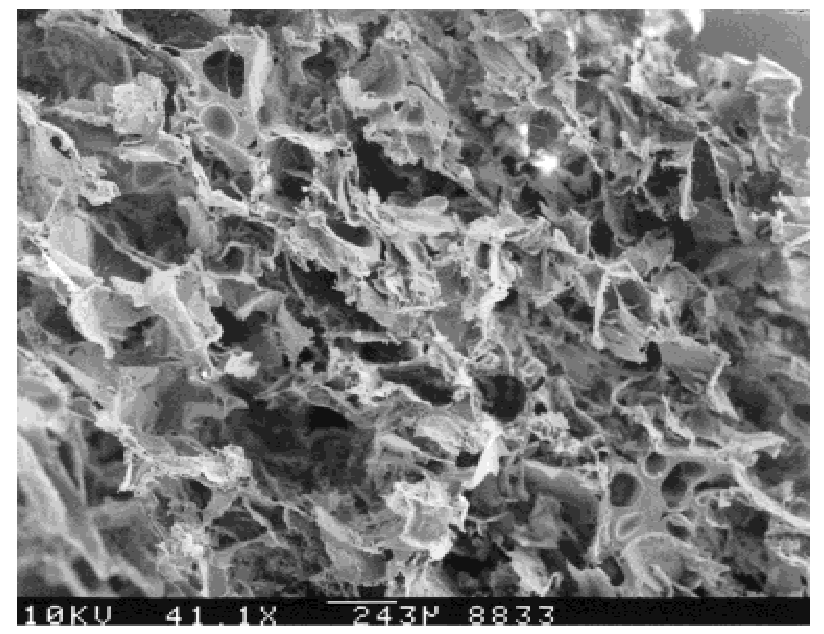

(b)

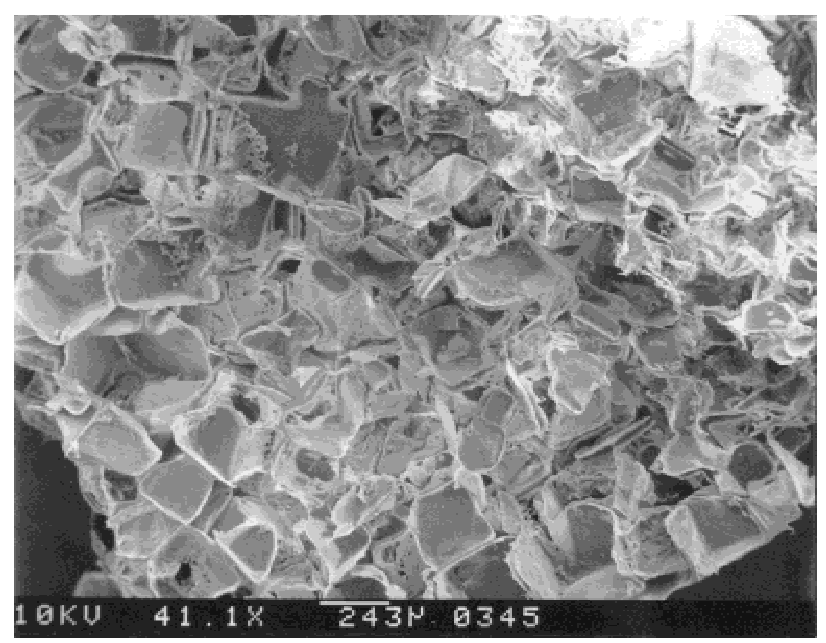

(c)

Figure 1. Scanning electron photomicrographs of crosssections of polymer matrices fabricated using (a) gas foaming method; (b) GF/PL method; and (c) SC/PL method. Size bars and original magnification are shown on photomicrographs. The nonporous external layer of polymer is visible in (a) (arrow). 
PL technique [Fig. 1(c)]. The GF/PL process results in matrices with two levels of porosity: interconnected macropores are created by leaching of the $\mathrm{NaCl}$ particles, and smaller, closed pores are created by the nucleation and growth of gas pores within the polymer particles (Fig. 2).

The pore structure of matrices formed from the SC/ PL process often is not uniform throughout the matrix due to evaporation of the organic solvent and a subsequent increase in the polymer concentration of the remaining solution entrapped within the salt bed. For example, the surface of these matrices that is adjacent to the glass coverslip during processing typically is less porous than the remainder of the matrix [Fig. 3(a)]. In contrast, the pore structure of gas foamedparticulate leached (GF/PL) matrices was uniform throughout the matrix and on the exterior surfaces [Fig. 3(b,c)]. TGA analysis of matrices indicated that negligible amounts of $\mathrm{NaCl}$ remained after leaching. To confirm that the gas foaming was responsible for the formation of stable matrices, control samples were compression molded but not foamed. Leaching of the $\mathrm{NaCl}$ from these matrices led to complete breakdown of the matrices (not shown).

The ratio of $\mathrm{NaCl} / \mathrm{PLGA}$ and the size of $\mathrm{NaCl}$ particles in GF/PL matrices next were varied to determine the range of porosity and pore structure that could be obtained with this process (Table I). The gross porosity of these matrices increased from $85.1 \%$ \pm 2.3 to $96.5 \% \pm 0.5$ as the ratio of $\mathrm{NaCl} /$ PLGA was similarly increased. At constant $\mathrm{NaCl}(95 \%)$, the increase in salt particle diameter had very little effect on the overall porosity. However, as the salt diameter was increased, the pore size increased in parallel (Table II). Mercury intrusion porosimetry also was utilized to confirm the open pore nature of matrices

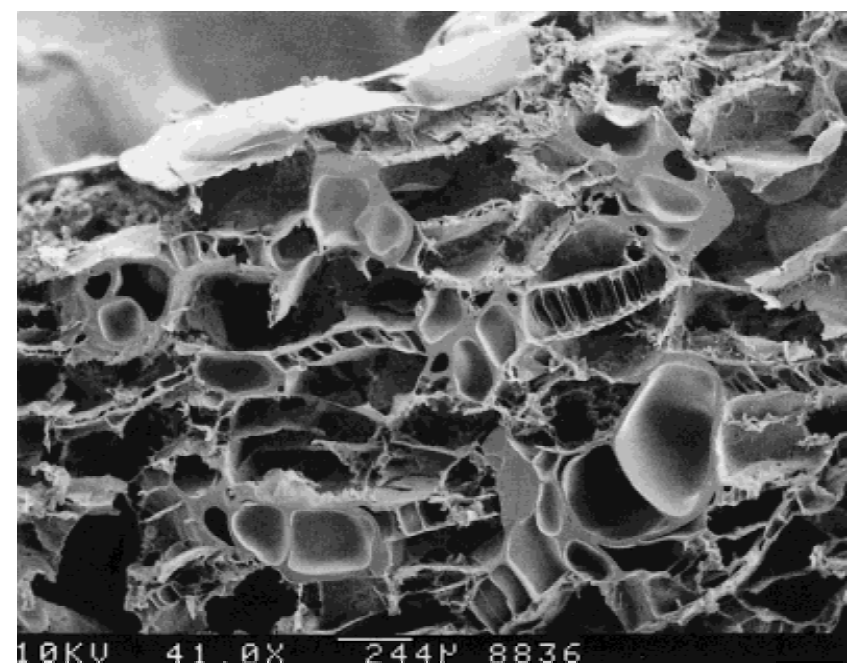

Figure 2. High magnification scanning electron photomicrograph of GF/PL matrix demonstrating macropores, formed by leaching of $\mathrm{NaCl}$ particles, and smaller pores formed by the gas pores within the polymer particles.

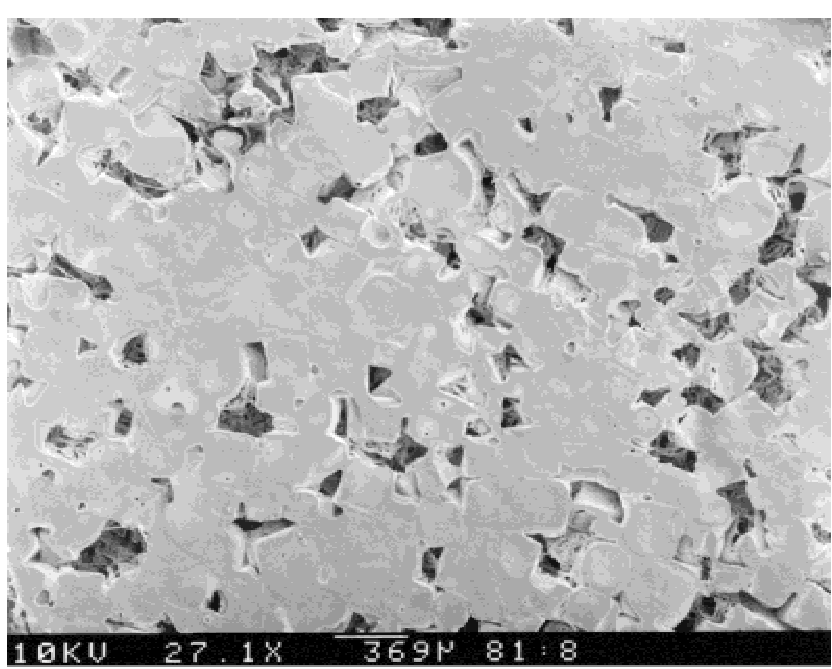

(a)

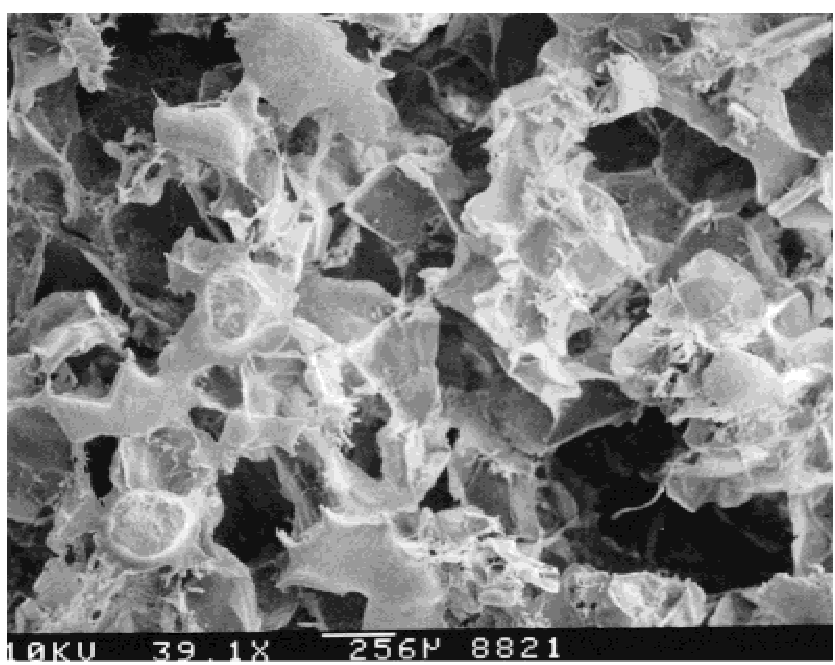

(b)

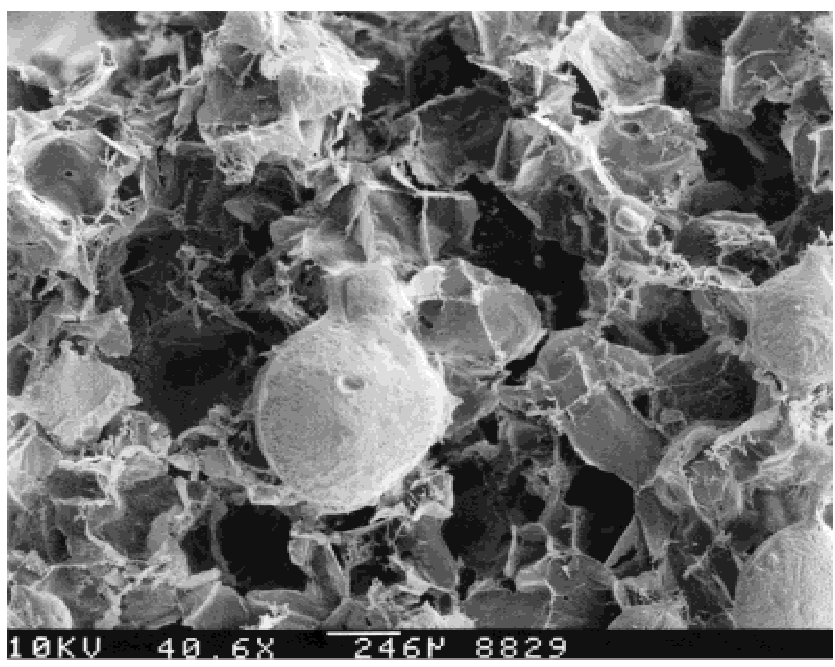

(c)

Figure 3. Scanning electron photomicrographs of (a) less porous surface of SC/PL matrix, (b) one surface of GF/PL matrix, and (c) other surface of GF/PL matrix. 
TABLE I

Porosity of GF/PL Matrices Fabricated With Various $\mathrm{NaCl} / \mathrm{PLGA}$ Ratios and $\mathrm{NaCl}$ Particle Size

\begin{tabular}{|c|c|c|c|}
\hline $\begin{array}{c}\mathrm{NaCl} \\
\text { Concentration } \\
(\%)\end{array}$ & \multicolumn{3}{|c|}{$\begin{array}{c}\mathrm{NaCl} \\
\text { Diameter }(\mu \mathrm{m})\end{array}$} \\
\hline 80 & - & $85.1 \pm 2.3$ & - \\
\hline 90 & $87.3 \pm 1.9$ & $91.5 \pm 1.4$ & - \\
\hline 95 & $93.9 \pm 0.9$ & $94.6 \pm 0.9$ & $95.0 \pm 0.8$ \\
\hline 97 & - & $96.5 \pm 0.5$ & - \\
\hline
\end{tabular}

formed with the GF/PL process. Matrices with a porosity of $95 \pm 1 \%$ (determined using gross measurements and weights) were measured to have a porosity of $89 \pm 1 \%$ with porosimetry. Mercury porosimetry only measures the pore volume consisting of interconnected pores, and this finding substantiates the interconnected pore structure of GF/PL matrices observed with SEM (Fig. 1). The slight decrease in porosity measured with porosimetry likely reflects the closed pores contained within the polymer particles (Fig. 2), which are not measured with porosimetry but are measured with overall porosity calculations.

Next the stability of the matrices was assessed using compressive and tensile mechanical tests. In general, the GF/PL matrices exhibited improved mechanical properties as compared to the SC/PL matrices (Fig. 4). The average compression modulus was $159 \pm 130 \mathrm{kPa}$ and $289 \pm 25 \mathrm{kPa}$ for the SC/PL and GF/PL matrices, respectively. The average tensile modulus was $334 \pm$ $52 \mathrm{kPa}$ for the SC/PL matrices and $1100 \pm 236 \mathrm{kPa}$ for the GF/PL matrices (Table III). These data represent an $82 \%$ increase in compression strength and a $229 \%$ increase in tensile strength.

\section{Tissue development on synthetic matrices}

The ability of the GF/PL matrices to allow cell adhesion and tissue formation was assessed in an in vitro study. SMCs adhered to the GF/PL matrix and covered the available surface area following seeding [Fig. $5(\mathrm{a})]$. The average cell density was $1.71 \times 10^{7} \mathrm{cells} / \mathrm{cm}^{3}$ after the cell seeding for $36 \mathrm{~h}$ and $3.05 \times 10^{7} \mathrm{cells} / \mathrm{cm}^{3}$

TABLE II

Pore Diameter of Polymer Matrices Fabricated Using GF/PL Process With Various NaCl Particles

\begin{tabular}{cc}
\hline $\begin{array}{c}\mathrm{NaCl} \text { Diameter } \\
(\mu \mathrm{m})\end{array}$ & $\begin{array}{c}\text { Pore Diameter } \\
(\mu \mathrm{m})^{*}\end{array}$ \\
\hline $106<\mathrm{d}<250$ & $193 \pm 94$ \\
$250<\mathrm{d}<425$ & $360 \pm 85$ \\
$\mathrm{~d}>425$ & $439 \pm 93$ \\
\hline
\end{tabular}

*Sponges in all cases were formed with a $\mathrm{NaCl} /$ polymer ratio of 19:1.

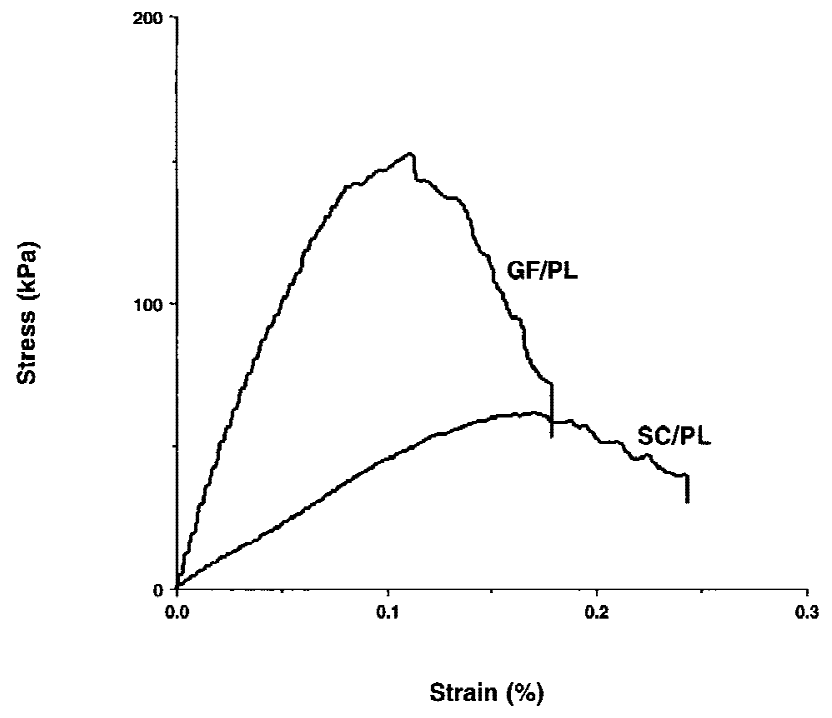

Figure 4. Typical stress-strain curve of SC/PL and GF/PL matrices subjected to a tensile load ( $1 \mathrm{~mm} / \mathrm{min})$. Both SC/ PL and GF/PL matrices had a porosity of $95 \%$ and were fabricated with the same size $\mathrm{NaCl}$ particles.

after 2 weeks in culture. This is a $78 \%$ increase in cell density. The cells filled the pores of the matrix and created a new three-dimensional tissue within the synthetic matrix. Most of the cell growth occurred around the periphery of the matrix in a relatively uniform manner, and a low cell concentration was observed in the center of the matrices at 2 weeks [Fig. 5(b)]. There was no observed change in the size and shape of the matrices over this time period.

\section{DISCUSSION}

Highly porous, open-pore matrices can be formed by utilizing a combined GF/PL process. This method avoids the use of organic solvents and high temperatures. The porosity and pore size of these matrices can be regulated by the salt/polymer ratio and salt particle size, and the pore structure is more uniform than that obtained with matrices fabricated with a standard SC/PL technique. Furthermore, these matrices exhibit better mechanical properties than those fabricated

TABLE III

Mechanical Properties of Matrices Fabricated With SC/PL or GF/PL Process

\begin{tabular}{lccc}
\hline & $\begin{array}{c}\text { Compressive } \\
\text { Modulus } \\
(\mathrm{kPa})\end{array}$ & $\begin{array}{c}\text { Modulus } \\
(\mathrm{kPa})\end{array}$ & $\begin{array}{c}\text { Elongation @ Break } \\
(\%)\end{array}$ \\
\hline SC/PL & $159 \pm 130$ & $334 \pm 52$ & $17.5 \pm 1.9$ \\
GF/PL & $289 \pm 25$ & $1100 \pm 236$ & $12.0 \pm 1.3$ \\
\hline
\end{tabular}

*Both types of matrices were fabricated with the same size $\mathrm{NaCl}$ particles, and both were $95 \%$ porous. 


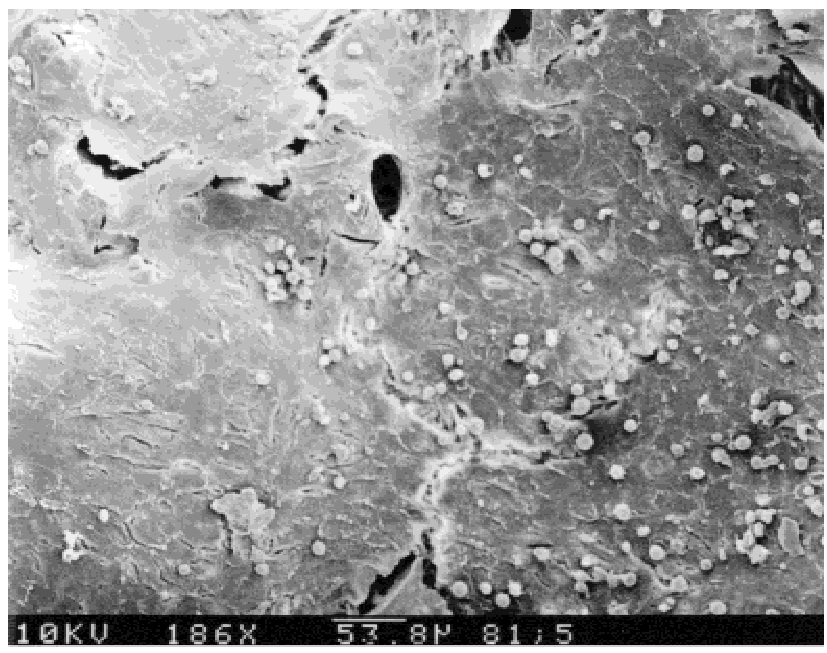

(a)

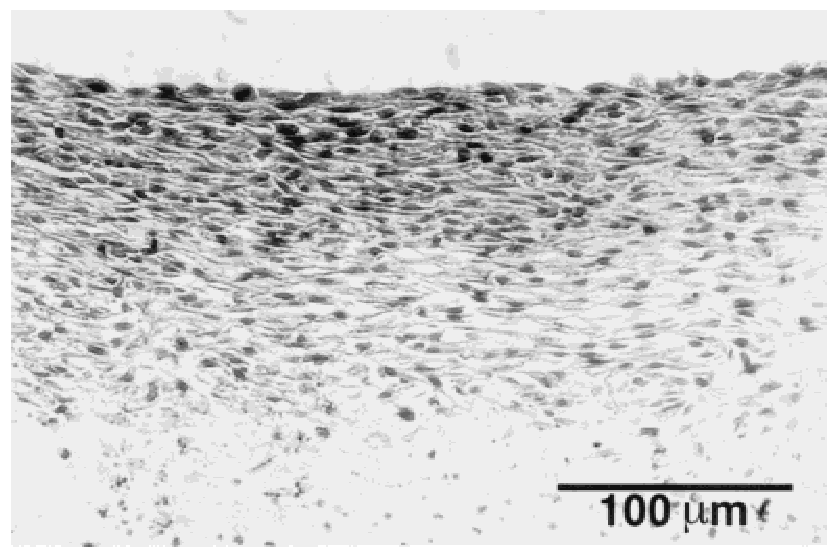

(b)

Figure 5. Photomicrographs of (a) smooth muscle cells adherent to the surface of the GF/PL matrix immediately following the cell seeding period of $36 \mathrm{~h}$, (b) hemotoxylin- and eosin-stained cross-section of new tissue formed by smooth muscle cells on GF/PL matrices after 2 weeks in culture (original magnification 400×).

with a standard SC/PL technique. Cells readily adhere to these matrices and form new threedimensional tissues within these porous structures.

Combining two elements of previously described techniques-particulate leaching with high pressure gas foaming-has made it possible to fabricate uniform, interconnected pore matrices. The SC/PL method yields a highly porous, closed pore matrix. The mechanism of pore formation with gas foaming involves three basic steps: (1) polymer/gas solution formation, (2) pore nucleation, and (3) pore growth and density reduction. ${ }^{10}$ The polymer/gas solution is formed by subjecting the polymer to high pressure $\mathrm{CO}_{2}$ gas (800 psi) and allowing it to saturate with gas $(48 \mathrm{~h})$. A thermodynamic instability is achieved by lowering the gas pressure to ambient. The gas phase separates from the polymer via pore nucleation and growth of the pores caused by diffusion of gas in areas of the polymer adjacent to the nucleation sites. The pore growth in turn reduces the polymer density. However, this leads to a predominantly closed-pore structure. In the current study, the polymer particles in the compressed polymer/ $\mathrm{NaCl}$ disk fuse as they expand during foaming, leading to a continuous polymer matrix. The subsequent leaching of the salt particles leads to an interconnected pore structure. The porosity of the matrix is controlled largely by the ratio of $\mathrm{NaCl} /$ PLGA, and the pore size is controlled by the size of the $\mathrm{NaCl}$ particles. Structurally stable matrices with very high porosities (up to $97 \%$ ) can be achieved with this approach.

GF/PL matrices exhibit more uniform pore structure and enhanced mechanical properties as compared to SC/PL matrices. The SC/PL matrices typically do not have a uniform pore structure due to the uneven distribution of polymer and $\mathrm{NaCl}$. In contrast, GF/PL matrices exhibit a completely uniform pore structure. This suggests that the polymer particles foamed uniformly throughout the salt bed. GF/PL matrices are stiffer than SC/PL matrices but have a lower elongation at break. The decrease in the maximum strain is not surprising as the flexibility of polymers generally decreases with increasing strength. There are three possible reasons for the mechanical properties of GF/ PL matrices being better than those of the SC/PL matrices. First, more uniform pore distribution of the GF/ PL matrices may improve the mechanical properties of polymer matrices. Stress applied to the porous materials is concentrated at the pore interface, and if the pore distribution is not uniform, polymer matrices typically deform at a lower stress. ${ }^{11}$ Second, the high pressure during GF/PL matrix fabrication may induce a closer packing of polymer chains, ${ }^{12}$ and/or tensile alignment of the polymer chains may be occurring during the elongation that occurs during foaming. ${ }^{13}$ Third, the residual chloroform in the SC/PL matrices may function as a plasticizer and make the polymer more ductile.

Smooth muscle cells readily adhered to these matrices and formed three-dimensional tissues within the porous structures. Smooth muscle cells proliferated during this process, but after culture for 2 weeks cell density had increased by only $78 \%$. The relatively low increase in cell density likely is due to the high initial cell seeding density $\left(1.71 \times 10^{7}\right.$ cell $\left./ \mathrm{cm}^{3}\right)$, which resulted in an almost completely confluent cell layer on the matrices following seeding [Fig. 5(a)]. In addition, diffusional limitations of nutrient transport to the cells inside the matrices may be responsible for this finding. The in vitro experiments in the present study indicated concentrated cell growth around the periphery of the matrix. This likely is due to $\mathrm{O}_{2}$ limitations at the center of these thick matrices $(3.4 \mathrm{~mm})$ once a high density is achieved. These types of matrices are vascularized following implantation in vivo, ${ }^{14}$ and this transport limitation thus may be avoided. Other techniques (SC/PL 
and phase separation) have been used to fabricate matrices for a variety of cell transplantation applications, including hepatocytes, ${ }^{15,16}$ chondrocytes, ${ }^{5}$ and osteoblasts. ${ }^{17}$ Matrices fabricated with the GF/PL process will be useful in all of these applications and likely will perform better due to their enhanced mechanical properties.

A potential advantage of the GF/PL process, as compared to other processing techniques, is that this process is likely to lead to less denaturation of the growth factors incorporated within the matrix. Organic solvents that remain in matrices following other processes may damage transplanted cells and nearby tissue, and exposure to organic solvents would inactivate many biologically active factors. Previously described approaches to the delivery of protein growth factors to transplanted cells using polymer microspheres also expose the growth factors to solvents. ${ }^{18}$ However, it will be necessary to confirm that the GF/ PL conditions (e.g., high pressure) do not have detrimental effects on incorporated proteins.

\section{CONCLUSIONS}

Highly porous matrices can be fabricated from PLGA with a combination of gas foaming and particulate leaching. This method avoids the use of organic solvents or high temperatures and yields desirable pore structures. It is possible to control the porosity and pore structure of these matrices by varying the salt/polymer ratio and salt particle size. These matrices exhibits enhanced mechanical properties and can be utilized to form three-dimensional tissues. This novel fabrication method may provide an ideal system for drug and/or growth factor incorporation into polymers used as tissue engineering matrices.

Financial support was provided by a GEM Consortium fellowship (LDH). The authors thank Ms. Andrea Brown for technical assistance. We also thank Dr. Antonios Mikos, Dr. Markus Widmer, and Mr. Nick Hutson for their assistance with matrix characterization.

\section{References}

1. R. Langer and J. P. Vacanti, “Tissue engineering," Science, 260, 920-926 (1993).
2. D. K. Gilding, "Biodegradable polymers" in Biocompatibility of Clinical Implant Materials, D. F. Williams (ed.), CRC Press, Inc., Boca Raton, Florida, 1981, pp. 209-232.

3. A. G. Mikos, A. J. Thorsen, L. A. Czerwonka, Y. Bao, and R. Langer, "Preparation and characterization of poly(L-lactic acid) foams," Polymer, 35, 1068-1077 (1994).

4. H. Lo, M. S. Ponticiello, and K. W. Leong, "Fabrication of controlled release biodegradable foams by phase separation," Tissue Eng., 1, 15-28 (1995).

5. L. E. Freed, G. Vunjak-Novakovic, R. J. Biron, D. B. Eagles, D. C. Lesnoy, S. K. Barlow, and R. Langer, "Biodegradable polymer scaffolds for tissue engineering," Bio/Technolog,y 12, 689-693 (1994).

6. D. J. Mooney, D. F. Baldwin, N. P. Suh, J. P. Vacanti, and R. Langer, "Novel approach to fabricate porous sponges of poly(D,L-lactic-co-glycolic acid) without the use of organic solvents," Biomaterials, 17, 1417-1422 (1996).

7. D. F. Baldwin, M. Shimbo, and N.P. Suh, "The role of gas dissolution and induced crystallization during microcellular polymer processing: A study of poly(ethylene terephthalate) and carbon dioxide systems," J. Eng. Mater. Technol., 117, 62-74 (1995).

8. A. Rothman, T. J. Kulik, M. B. Taubman, B. C. Berk, C. W. J. Smith, and B. Nadal-Ginard, "Development and characterization of a cloned rat pulmonary arterial smooth muscle cell line that maintains differentiated properties through multiple subcultures," Circulation, 86, 1977-1986 (1992).

9. Y.-J. Kim, R. L. Y. Sah, J.-Y. H. Doong, and A. J. Grodzinsky, "Fluorometric assay of DNA in cartilage explants using Hoechst 33258," Anal. Biochem., 174, 168-176 (1988).

10. B. Park, D. F. Baldwin, and N. P. Suh, "Effect of the pressure drop rate on cell nucleation in continuous processing of microcellular polymers," Polym. Eng. Sci., 35, 432-440 (1995).

11. A. J. Kinloch and R. J. Young, Fracture Behavior of Polymers, Elsevier Applied Science, New York, 1985.

12. F. Rodriguez, Principles of Polymer Systems, McGraw-Hill Book Company, New York, 1982, pp. 264-266.

13. R. C. Thomson, M. J. Yaszemski, and A. G. Mikos, "Polymer scaffold processing," in Principles of Tissue Engineering R. P. Lanza, R. Langer, and W. L. Chick (eds.), Academic Press, Inc., San Diego, California, 1997, p. 264.

14. A. G. Mikos, G. Sarankinos, M. D. Lyman, D. E. Inger, J. P. Vacanti, and R. Langer, "Prevascularization of porous biodegradable polymers," Biotech. Bioeng., 42, 716-723 (1993).

15. D. J. Mooney, P. M. Kaufmann, K. Sano, K. M. McNamara, J. P. Vacanti, and R. Langer, "Transplantation of hepatocytes using porous biodegradable sponges," Transplant. Proc., 26, 34253426 (1994).

16. D. J. Mooney, S. Park, P. M. Kaufmann, K. Sano, K. McNamara, J. P. Vacanti, and R. Langer, "Biodegradable sponges for hepatocyte transplantation," J. Biomed. Mater. Res., 29," 959-965 (1995).

17. S. L. Ishaug, M. J. Yaszemski, R. Bizios, and A. G. Mikos, "Osteoblast function on synthetic biodegradable polymers," $J$. Biomed. Mater. Res., 28, 1445-1453 (1994).

18. D. J. Mooney, P. M. Kaufmann, K. Sano, S. P. Schwendeman, K. Majahod, B. Schloo, J. P. Vacanti, and R. Langer, "Localized delivery of epidermal growth factor improves the survival of transplanted hepatocytes," Biotech. Bioeng., 50, 442-449 (1996). 